\title{
Hereditary Factor XIII Deficiency
}

National Cancer Institute

\section{Source}

National Cancer Institute. Hereditary Factor XIII Deficiency. NCI Thesaurus. Code C98941.

A rare autosomal recessive inherited blood coagulation disorder characterized by deficiency of factor XIII, resulting in bleeding. 